\title{
CONTROL AT THE CARDIA
}

\author{
RichaRd K. GREENWOOD, M.D., M.Chir., F.R.C.S. \\ Surgical Tutor \\ *St. Thomas' Hospital Medical School, London, S.E.1.
}

DESPITE many recent advances, a thorough understanding of the physiological action of the lower segment of the oesophagus is still incomplete. The precise location of the gastroesophageal junction requires definition. Clearly it is where oesophagus terminates and stomach commences. Unfortunately there is no unanimity of opinion on this matter. Barrett (1958) defines the oesophagus as the tubular structure interposed between the pharynx and bag of the stomach, receiving its blood supply from the aorta rather than the left gastric artery and having no peritoneal covering. This places the gastroesophageal junction at the level of the incisuria cardia where the fundus of the stomach commences (Ingelfinger 1958). The opening into the stomach is referred to as the cardiac orifice and the region immediately above it as the cardia. Earlier however Barrett (1950) had suggested that the mucosal junction offered a convenient and distinct landmark between the two organs. He and Palmer (1953) postulated that anything lined with squamous epithelium was oesophagus, and any structure with gastric glandular mucosa was stomach. The mucosal junction however bears little relation to the structure and function of the underlying muscle.

\section{Anatomy of the Gastroesophageal Junction}

The oesophagus of man is a tubular structure with a muscular wall. (Fig. 1) The muscle is arranged in two layers, an inner circular and an outer longitudinal. In the upper part of the organ the muscle is striated but in the middle third there is a gradual transition from striated to smooth, the lower end consisting entirely of smooth muscle (Arey and Tremaine, 1933). At the level of the cardiac orifice of the stomach the muscle fibres in the wall are arranged in a loop encompassing the anterior, lateral and posterior aspects of the organ. These are variously referred to as the loop of Willis (1674), or collar of Helvitius.

The oesophagus passes through the dia-

*Present Address: Leicester General Hospital

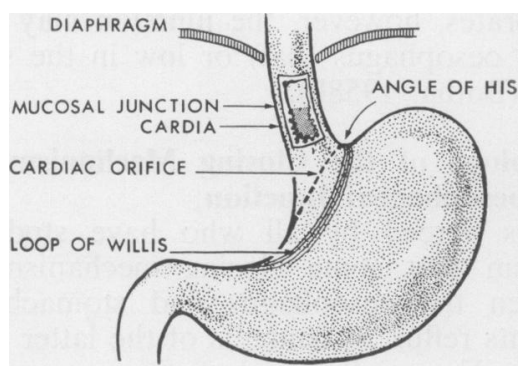

FIG. 1.-Anatomy of the gastroesophageal junction.

phragmatic hiatus to enter the abdomen. As it does so it deviates forwards and to the left. The oesophageal opening in the diaphragm is closed by the phreno-esophageal membrane. This is morphologically part of the transversalis ? fascia which lines the interior of the whole abdominal cavity. It passes from the undersurface of the diaphragm to the wall of the oesophagus where it splits into ascending and descending fibres which eventually merge with the muscle in the wall. Anders and Bahrmann (1932) noted many elastic fibres in the membrane, but its texture and significance are disputed. Allison (1951), believes it to be a tough structure of considerable importance in restraining the stomach within the abdomen. Barrett (1954) however, considers it to be too delicate to play any part in preventing sliding hiatal herniation.

The mucosal junction is clearly discernible on the inner aspect of the two organs. The stratified epithelium of the oesophagus is white, the columnar mucosa of the stomach reddish brown. The two meet at an irregular but easily definable line. The precise location of the columno-squamous junction in relation to both the cardiac orifice of the stomach and the diaphragm in the living human is disputed (Allison and Johnstone, 1953; Palmer, 1953; Creamer, Harrison and Pierce, 1959). It is probable that the lower $2 \mathrm{~cm}$. of tubular "gullet" normally has a columnar lining and that the 
epithelial junction lies just below the oesophageal hiatus of the diaphragm. It is agreed that there may be variations in the precise location from individual to individual, and also possibly in the same individual from time to time owing to the muscular activity of the muscularis mucosa (Palmer, 1953; Nauta, 1955; Allison, 1956). In this connection it is interesting to note that the mucosal junction in the dog is located at a similar level to that in man, at or just below the oesophageal hiatus. In other vertebrates, however, the junction may be high in the oesophagus (bat) or low in the stomach (rat). (Botha, 1958b).

\section{Physiology of the Closing Mechanism at the Gastroesophageal Junction}

It is agreed by all who have studied the problem that some closing mechanism exists between the oesophagus and stomach which prevents reflux of contents of the latter into the former. Essentially the hypotheses propounded to account for gastroesophageal competence may be grouped under certain headings:

1. The presence of a morphological sphincter.

2. Mechanical factors.

3. The presence of an intrinsic physiological sphincter.

\section{Morphological Sphincter}

Two varieties of anatomical sphincter have been considered as factors responsible for closure of the gastroesophageal junctionintrinsic and extrinsic.

(a) Intrinsic. A constriction in the wall of the lower human oesophagus near the gastroesophageal junction has been reported by a number of workers. (Laimer, 1883; Lerche, 1950; Nauta, 1955). Most of the studies have been carnied out on cadavers and accounts of the relationship of the narrowing to the diaphragmatic hiatus have varied. The cause of the narrowing has been reported as a localised muscle thickening. (Hurst, 1925; Anders and Bahrmann, 1932; Lerche, 1950). Other investigators have been unable to confirm these findings (Lendrum, 1937; Peters, 1955) and most authorities now agree that there is no morphological sphincter in the wall of the human oesophagus. It is interesting to note however that such anatomical sphincters do exist in certain species, e.g., the bat. (Fischer, 1909).

(b) Extrinsic. It has been suggested thrt the diaphragm might act as an external sphincter upon the lower oesopnagus. Two mechanisms have been postulated in this connection.
The first is that of a pinchcock action. This hypothesis was put forward by Jackson (1922) who suggested a side-to-side compression between the two pillars of the crus. This has been noted at oesophagoscopy and could account for the hold-up at the level of the diaphragm sometimes noted during barium swallows (Johnstone, 1955). This pinchcock action of the diaphragm is far from constant and is observed only during inspirationJoannides (1929) postulated a milking action of the pillars of the crus on the walls of the oesophagus during inspiration. Dornhorst, Harrison and Pierce (1954) and Braasch and Ellis (1956) however, have been unable to detect any gripping action of the diaphragm during inspiration.

The other sphincteric action attributed to the diaphragm was propounded by Allison (1951). He likened the gastroesophageal junction to the ano-rectal junction. In both sites the alimentary canal changes direction and passes through a muscular diaphragm (the diaphragm and pubo-rectalis). It was postulated that the right crus of the diaphragm which lassoes the cardiac angle and hitches it to the lumbar spine (Collis, Satchwell and Abrams, 1954) might compress the gastroesophageal junction directlo or serve to maintain the angle of entry o oesophagus into the stomach and enable this to function as a mechanical flap valve (vide infra).

\section{Mechanical Factors}

(a) Oblique entry of oesophagus into stomach. The cardiac angle or angle of His (19v3) has been considered an important antireflux factor by many observers. When the angle is acute, distension of the stomach tends to close the gastroesophageal junction in a valve-like fashion by forcing the intraluminal projection created by the angle against the opposite oesophageal wall (Von Gubaroff, 1886; Dick and Hurst, 1942 and Barrett, 1954). Marchand (1955) believed that the cardiac angle acted purely mechanically and was a passive phenomenon. He demonstrated that the cardia was competent in the cadaver provided that the angle of His was not obliterated. This work has not been substantiated, however, and it is difficult to see how the angle can form an effective barrier unless it is maintained by some active means. Many believe that the diaphragm fulfills this role, and certainly the angle is lost in the presence of a hiatal hernia. Smiddy and Atkinson (1960) however showed that the angle persisted after the gastroesophageal junction had been completely freed 
from the diaphragm. They believe that the oblique fibres constituting the loop of Willis maintain the oesophago-gastric angle by acting as a sling around the cardia. Disruption of the oblique fibres of the gastric muscle coat on the lateral side of the cardia renders the latter more susceptible to reflux. Similar results were reported by Gahagan (1962).

It is interesting to note however that the cardiac angle is a late evolutional development, being present only in reptiles and mammals (Botha, 1958b). It is possible therefore that the distribution of the sling fibres along the lesser curvature of the stomach may be a result of the angle rather than its cause as certain lower animals have an incisura but no sling fibres.

(b) Mucosal Folds at the Cardia. The presence of a mucosal rosette at the cardia has been put forward as a mechanical factor preventing reflux. On distending the stomach the folds are ironed out as the cardiac orifice is opened. (Nauta, 1956). Barrett (1954), Creamer, (1955) and Botha (1958a) all believe that a mucosal rosette plugging the cardiac orifice is actively maintained by tone in the underlying muscularis mucosa. Allison (1956) however points out that the mucosal apposition may be secondary to external compression of the region by the diaphragm, competence depending not on the mucosal rosette but on the muscular action which produces it.

(c) Flaccid Intra-abdominal Oesophagus. The existence of a segment of oesophagus lying within the abdomen has been disputed (Allison, 1948). Confusion on the matter may have been due in part to disagreement on the precise peritoneal relations of the gastroesophageal junction (Barrett, 1958). These latter however do not alter the pressure effects, and it is now accepted that a portion of tubular "gullet" lies within the abdomen and is subject to a different pressure atmosphere than the rest of the oesophagus above the diaphragm (Dornhorst and others, 1954). On inspiration the pressure within the thoracic cavity falls, whereas that within the abdomen rises. The point at which the inspiratory pressure changes reverse in direction may be referred to as the effective diaphragmatic hiatus and it coincides with the site of hold-up on swallowing which can be demonstrated radiologically (Creamer and others, 1959).

The abdomen behaves as a fluid cavity. In the head down position the external pressure applied to the flaccid intra-abdominal oesophagus at the bottom of the abdominal cavity is greater than intragastric pressure and hence the segment remains closed. (Cannon, 1911; Fyke, Code and Schlegel, 1956). It has been suggested that individuals without an intraabdominal oesophagus are particularly susceptible to gastroesophageal reflux when intraabdominal pressure is increased (Wolf, 1960). It is possible that the distance separating the diaphragmatic hiatus and cardiac orifice may vary and factors which shorten this distance may facilitaate retrograde flow, e.g., pregnancy (Nagler and Spiro, 1961).

\section{Intrinsic Physiological Sphincter}

In recent times progressively more attention has been directed to the possibility of a physiological sphincter existing between the oesophagus and stomach. Kronecker and Meltzer (1883) are accredited with the first scientific manometric study of the lower oesophagus, but it was not until improved techniques were available that a zone of elevated pressure was detected at the gastroesophageal junction (Fyke and others, 1956; Botha, Astley and Carré, 1957; 'Atkinson, Edwards, Honour and Rowlands, 1957a) (Fig. 2, lower left panel). Ait rest this zone of elevated pressure is 4 to 5 $\mathrm{cm}$. wide as measured by a small $0.5 \mathrm{~cm}$. diameter water-filled balloon (Code and Schlegel, 1958). The pressure is greater at the end of expiration than at the end of inspiration, maximal pressures of 80 and $60 \mathrm{~cm}$. of water being recorded at, and just below, the effective diaphragmatic hiatus respectively (Fyke and others, 1956) (Fig. 2, upper panel). This pressure barrier between stomach and oesophagus is maintained despite changes in the posture of the individual. That the diaphragm alone is not responsible for the zone of increased pressure may be shown by the fact that phrenic paralysis is without effect upon it, (Atkinson and Sumerling, 1959) and that the sphincter can still be detected in cases of hiatal herniation where the gastroesophageal junction is displaced above the diaphragm (Atkinson, Edwards, Honour and Rowlands, 1957b; Code, Kelly, Schlegel and Olsen, 1962).

The response to deglutition of the zone of elevated pressure at the gastroesophageal junction indicates that it possesses the physiological characteristics of a sphincter. Unlike the body of the oesophagus which responds with a peristaltic wave of contraction, its initial response is one of relaxation. The pressure falls immediately deglutition takes place and remains low until the peristaltic complex reaches it from the oesophagus above. The area then 


\section{PHYSIOLOGICAL SPHINCTER}
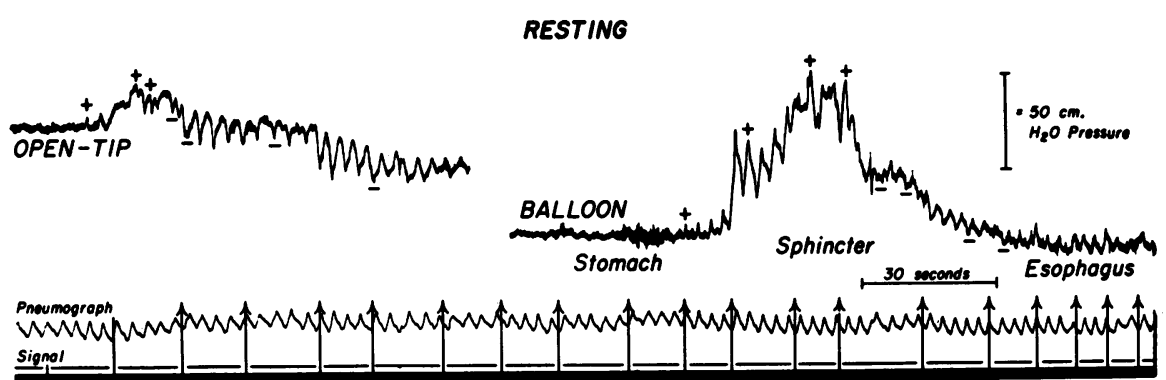

PRESSURE DETECTING PROBES

DEGLUTITION
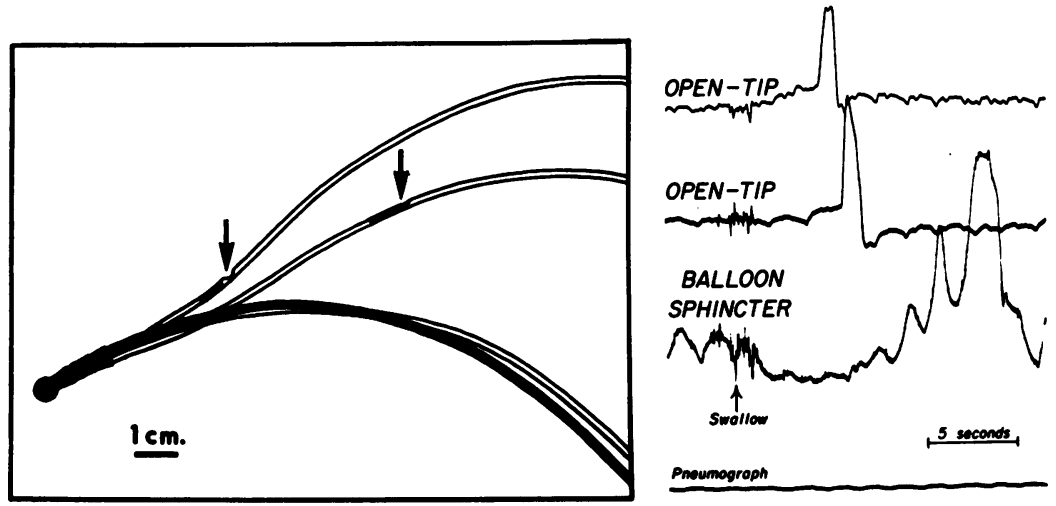

MANOMETRIC STUDY

\section{OF THE GASTROESOPHAGEAL JUNCTION}

FIG. 2.

Low Left Panel.

Pressure Detecting Probes.

Three small-caliber water-filled polyethylene tubes connected proximally to strain gauges. The open tip of the distal tube is covered with a small latex balloon $5 \mathrm{~mm}$. in diameter. The arrows indicate lateral orifices in the other tubes at intervals of $5 \mathrm{~cm}$. A fine wire within an extra tube is incorporated into the unit to give it some degree of rigidity.

Upper Panel

Resting Pressures.

Withdrawals of an open tip and balloon tipped tube are shown.

The upright arrows at each break in the base-line indicate $0.5 \mathrm{om}$. oral withdrawals of the detecting units through the gastroesophageal junctional zone. Respiratory excursions are recorded by a pneumograph, an upward deflection corresponding to inspiration. $(+)$ and $(-)$ signs indicate respectively positive and negative deflections with inspiration.

Note the sharp change in direction of the pressure swings from $(+)$ to $(-)$ with inspiration and the distinct rise of pressure as the units traverse the sphincter.

Lower Right Panel

Pressure changes after deglutition.

Note the peristaltic sequence in the oesophagus and that the pressure in the sphincter declines and remains lowered until the wave of deglutition reaches it; the sphincter then closes with a prolonged contraction.

These manometric studies were carried out on a dog. The findings are similar in man.

responds with a prolonged contraction before returning to normal (Fyke and others, 1956; Atkinson and others, 1957b). (Figure 2 lower right panel).
A similar sphincteric mechanism to that found in man has also been demonstrated at the lower end of the oesophagus in a number of other animal species. The zone of elevated 


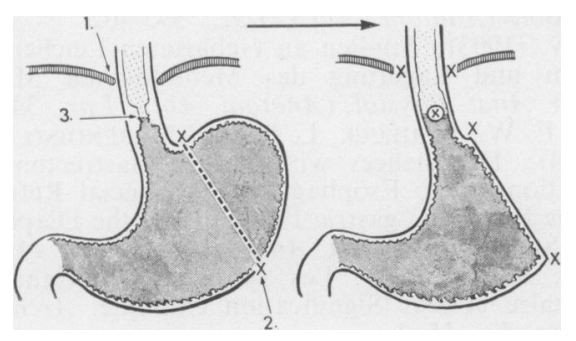

FIG. 3.-Experimental procedures.

1. Severence of junctional zone from diaphragm.

2. Obliteration of cardiac angle.

3. Removal of mucosal folds at the cardia. No reflux.

pressure however is usually narrower than in humans.

There is a good deal of experimental evidence in favour of a physiological sphincteric mechanism at the gastroesophageal junction. Hoag, Kiriluk and Merendino (1954), Braasch and Ellis (1956) and Meiss, Grindlay and Ellis (1958) have all shown that preservation of the gastroesophageal junotion is the most important factor in the prevention of reflux. Severance of the junctional zone from the diaphragm, obliteration of the cardiac angle, or removal of the mucosa at the cardiac orifice on the other hand are all without effect upon cardiac competence. (Figs. 3 and 4). The experiments of Ingram, Respess and Muller (1959) concerned with isolation of the lower oesophagus and junctional area as a blind pouch from the stomach support the concept that there is a mechanism at the lower end of the oesophagus which prevents reflux (Fig. 5).

\section{Summary}

An area has been detected at the gastroesophageal junction which exhibits the features of an intrinsic physiological sphincter. No corresponding morphological sphincter has been detected to account for these findings. It must therefore be postulated that the muscle at the lower end of the oesophagus, which outwardly does not differ from that of the rest of the organ, is invested with special physiological powers. Alternatively it is possible that the sphincteric properties reside within the muscularis mucosa of the region, or that the muscle fibres of the loop of Willis are of importance.

This physiological sphincter has been established as the principal factor responsible for competence at the gastroesophageal junction. It is now clear that the diaphragm plays only a secondary role in control at the cardia.

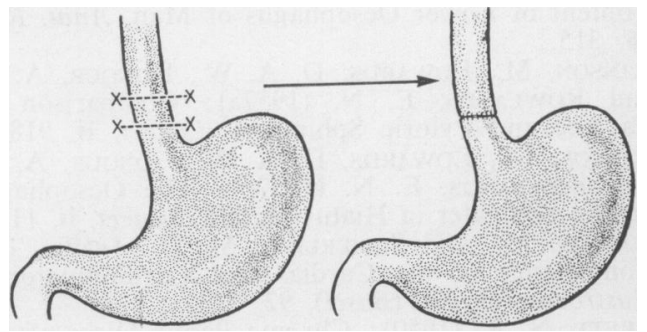

Fig. 4.-Experimental procedures.

Resection of gastroesophageal junction. Reflux.

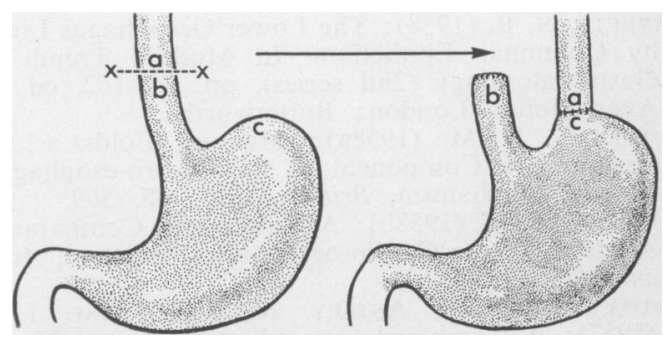

FIG. 5.-Experimental procedures.

Isolation of lower oesophagus and junctional area as blind pouch from the stomach.

Oesophagitis in main oesophagus (a)

No oesophagitis in blind pouch (b)

It is probable that the normal action ando attachments of the diaphragm restrain the? junctional zone within the abdomen where the physiological sphinoter can act to maximum advantage. The existence of an intra-abdominal segment of tubular "gullet" is of importance in this respect. Other mechanical factors such as the oblique angle of entry of oesophagus into stomach and mucosal folds at the cardia may contribute to competence of the junctional zone but their importance is limited.

I should like to thank Miss Dewe, Medical Artist to St. Thomas' Hospital and also the Department of Clinical Photography of St. Thomas' for their help in the preparation of the illustrations.

\section{REFERENCES}

Allison, P. R. (1948): Peptic Ulcer of the Oesophagus, Thorax, 3, 20.

Allison, P. R. (1951): Reflux Esophagitis, Sliding Hiatal Hernia, and the Anatomy of Repair, Surg. Gynec. Obstet., 92, 419.

Allison, P. R. (1956): Function and Dysfunction of the Cardia, Bull. Johns. Hopk. Hosp., 99, 182.

Allison, P. R. and Johnstone, A. S. (1953): The Oesophagus Lined with Gastric Mucous Membrane, Thorax, 8, 87.

ANDERS, H. E., and BaHRMANN, E. (1932): Uber die Sogenannten, Hiatushernien des Ziverchfells im Höheren Alter und ihre Genese, Z. klin. Med., 122, 736.

Arey, L. B., and Tremaine, M. J. (1933): Muscle 
Content of Lower Oesophagus of Man, Anat. Rec. 56, 315.

Atkinson, M., Edwards, D. A. W., Honour, A. J., and RowlandS, E. N. (1957a): Comparison of Cardiac and Pyloric Sphincters, Lancet, ii, 918.

Atkinson, M., Edwards, D. A. W., Honour, A. J., and Rowlands, E. N. (1957b): The Oesophagogastric Sphincter in Hiatus Hernia, Lancet, ii, 1138.

AtKinson, M., and Sumerling, M. D. $(1 \times 49)$ : The Competence of the Cardia after Cardiomyotomy, Gastroenterologia, (Basel), 92, 123.

Barrett, N. R. (1950): Chronic Peptic Ulcer of the Oesophagus and 'Oesophagitis', Brit. J. Surg., 38, 175.

BarretT, N. R. (1954): Hiatus Hernia-a Review of Some Controversial Points, Brit. J. Surg., 42, 231.

BARRETT, N. R. (1958): The Lower Oesophagus Lined by Columnar Epithelium. In Modern Trends in Gastroenterology (2nd series), pp. 147-162, ed. F. Avery Jones. London: Butterworth.

BothA, G. S. M. (1958a): Mucosal Folds at the Cardia as a Component of the Gastro-esophageal Closing Mechanism, Brit. J. Surg., 45, 569.

Botha, G. S. M. (1958b): A Note on the Comparative Anatomy of the Cardio-oesophageal Junction, Acta, anat. (Basel), 34, 52.

Botha, G. S. M., Astley, R., and Carre, I. J. (1957): A Combined Cineradiographic and Manometric Study of the Gastro-oesophageal Junction, Lancet, i, 659.

BraAsch, J. W., and Ellis, F. H. JR. (1956): The Gastroesophageal Sphincter Mechanism: An Experimental Study, Surgery, 39, 901.

Cannon, W. B. (1911): The Mechanical Factors of Digestion. New York: Longmans Green.

CODE, C. F., and Schlegel, J. F. (1958): The Pressure Profile of the Gastroesophageal Sphincter in Man: An Improved Method of Detection, Proc. Mayo Clin., 33, 406.

CoDe, C. F., Kelley, M. L. JR., SChlegel, J. F., and OLSEN, A. M. (1962): Detection of Hiatal Hernia during Esophageal Motility Tests, Gastroenterology, 43, 521 .

Collis, J. L., Satchwell, L. M., and Abrams, L. D. (1954): Nerve Supply to the Crura of the Diaphragm, Thorax, 9, 22.

Creamer, B. (1955): Oesophageal Reflux and the Action of Carminatives, Lancet, i, 590.

Creamer, B., Harrison, G. K., and Pierce, J. W. (1959): Further Observations on the Gastrooesophageal Junction, Thorax, 14, 132.

DICK, R. C. S., and HURST, A. (1942): Chronic Peptic Ulcer of the Oesophagus and its Association with Congenitally Short Oesophagus and Diaphragmatic Hernia, Quart. J. Med. n.s., 11, 105.

Dornhorst, A. C., Harrison, K., and Pierce, J. W. (1954): Observations on the Normal Oesophagus and Cardia, Lancet, i, 695.

FISCHER, H. (1909): Uber Functionelle Anpassung am Fledermausmagen, Pfügers Arch. ges. Physiol., 129, 113.

FyKe, F. E. JR., CODE, C. F., and SChlegel, J. F. (1956): The Gastroesophageal Sphincter in Healthy Human Beings, Gastroenterologia, (Basel), 86, 135 .

Gahagan. T. (1962): The Function of the Musculature of the Esophagus and Stomach in the Esophagogastric Sphincter Mechanism, Surg. Gynec. Obstet., 114, 293.

GUBAROFF, A. VON (1886): Ueber den Verschluss des Menschlichen Magens an der Cardia, Arch. Anat.
Physiol. (Anatom. Abt.), Lpz., 395-402.

HIS, W. (1903): Studien an Gehärteten Leichen über Form und Lagerung des Menschlichen Magens, Arch. Anat. Physiol. (Anatom. Abt.), Lpz., 345-367.

Hoag, E. W., KiriluCK, L. B., and Merendino, K. A. (1954): Experiences with Upper Gastrectomy, its Relationship to Esophagitis with Special Reference to the Esophago-gastric Junction and the Diaphragm -a Study in the Dog, Amer. J. Surg., 88, 44.

Hurst, A. F. (1925): Les Sphincters du Canal Alimentaire et leur Signification Clinique, Arch Mal. Appar. dig., 15, 1.

INGELFINGER, F. J. (1958): Esophageal Motility, Physiol. Rev., 38, 533.

INGRAM, P. R., ReSPeSS, J. C., and Muller, W. H. JR. (1959): The Role of an Intrinsic Sphincter Mechanism in the Prevention of Reflux Esophagitis, Surg. Gynec. Obstet., 109, 659.

JACKSON, C. (1922): The Diaphragmatic Pinchoock in So-called "Cardiospasm", Laryngoscope, (St. Louis), 32, 139.

JOANNIDES, M. (1929): Influence of the Diaphragm on the Esophagus and on the Stomach, Arch. intern. Med., 44, 856.

JoHNSTONE, A. S. (1955): Oesophagitis and Peptic Ulcer of the Oesophagus, Brit. J. Radiol. N.S., 28, 229.

KroneCKer, H. and Meltzer, S. J. (1883): Der Schluck-mechanisms, seine Erregung unde seine Hemmung, Arch, Anat. Physiol. (Physiol Abt.), Lpz., 328-362.

LAIMER, E. (1883): Beitrag zur Anatomie des Oesophagus, Med. Jb. Wien, 333.

LENDRUM, F. C. (1937): Anatomic Features of the Cardiac Orifice of the Stomach, Arch. intern. Med. 59, 474.

LERCHE, W. (1950): The Esophagus and Pharynx in Action, Springfield, Illinois: Charles C. Thomas.

MARCHAND, P. (1955): The Gastro-oesophageal "Sphincter" and the Mechanism of Regurgitation, Brit. J. Surg., 42, 504.

Meiss, J. H., Grindlay, J. H., and Ellis, F. H. JR. (1958): The Gastroesophageal Sphincter Mechanism 11. Further Experimental Studies in the Dog, $J$. thorac. Surg., 36, 156.

NAGLER, R., and SPIRO, H. M. (1961): Segmental Response of the Inferior Esophageal Sphincter to Elevated Intragastric Pressure, Gastroenterology, 40, 405.

NAUTA, J. (1955): Een Studie van het Afsluitingsmechanisme Tussen Slokdarm en Maag. Leiden: H. E. Stenfert Kroese.

NautA, J. (1956): The Closing Mechanism between the Oesophagus and Stomach, Gastroenterologia, (Basel), 86, 219.

Palmer, E. D. (1953): Attempt to Localize Normal Esophagogastric Junction, Radiology, 60, 825.

Peters, P. M. (1955): Closure Mechanisms at the Cardia with Special Reference to the Diaphragmatico-oesophageal Elastic Ligament, Thorax, 10, 27.

SMidDy, F. G., and AtKinson, M. (1960): Mechanisms Preventing Gastro-oesophageal Reflux in the Dog, Brit. J. Surg., 47, 680.

WILLIS, T. (1674-5): Pharmacutice Rationale: Sive Diatiba de Medicamentorum Operationibus in Humano Corpore. Oxford (ed. in English 1679).

WOLF, B. S. (1960): The Esophagogastric Closing Mechanism: Role of the Abdominal Esophagus, $J$. Mt. Sinai Hosp., 27, 404. 